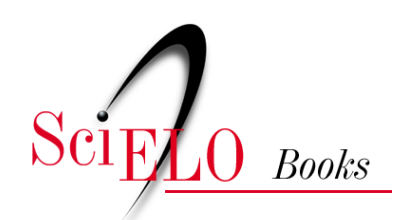

\title{
Entre decretos, disputas judiciais e conflitos armados batalhas entre Estado, camponeses e indígenas pela posse da Reserva Florestal de Nonoai/RS
}

\author{
Sandor Fernando Bringmann
}

\section{SciELO Books / SciELO Livros / SciELO Libros}

BRINGMANN, S.F. Entre decretos, disputas judiciais e conflitos armados: batalhas entre Estado, camponeses e indígenas pela posse da Reserva Florestal de Nonoai/RS. In: GERHARDT, M., NODARI, E.S., and MORETTO, S.P., eds. História ambiental e migrações: diálogos [online]. São Leopoldo: Oikos; editora UFFS, 2017, pp. 177-192. ISBN: 978-85-64905-68-9. https://doi.org/10.7476/9788564905689.0012.

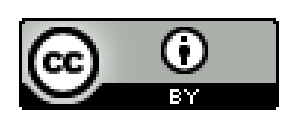

All the contents of this work, except where otherwise noted, is licensed under a Creative Commons Attribution 4.0 International license.

Todo o conteúdo deste trabalho, exceto quando houver ressalva, é publicado sob a licença Creative Commons Atribição $\underline{4.0}$.

Todo el contenido de esta obra, excepto donde se indique lo contrario, está bajo licencia de la licencia $\underline{\text { Creative Commons }}$ Reconocimento 4.0. 


\title{
Entre decretos, disputas judiciais e conflitos armados: batalhas entre Estado, camponeses e indígenas pela posse da Reserva Florestal de Nonoai/RS ${ }^{1}$
}

\author{
Sandor Fernando Bringmann
}

\section{Introdução}

Quem visualizar o mapa do Rio Grande do Sul através de imagens de satélite, mesmo distraidamente, verificará que muito pouco restou da Mata Atlântica que, em tempos pretéritos, cobriu parte significativa do seu território. Se em período anterior à ocupação europeia do território gaúcho o percentual coberto por este bioma chegou a $39,7 \%,{ }^{2}$ na atualidade, restam apenas 2,69\% de cobertura florestal (MARCUZZO et al., 1998). Este pequeno percentual encontra-se diluído em meio a lavouras, a centros urbanos, às áreas onde a agricultura mecanizada não alcança (morros e serras) ou ainda em reduzidos espaços destinados à conservação da flora e da fauna.

Em cada região do estado, a devastação da mata atlântica possui uma historicidade e uma temporalidade específicas. As regiões norte e noroeste, lócus geográfico deste artigo, compõem, em termos fisiográficos, os denominados Planalto Médio e Alto Uruguai (BORGES FORTES, 1959). Nelas, o processo de desmatamento teve início no final do século XIX, quando descendentes de imigrantes italianos e alemães, fugindo da escassez de terras das antigas colônias das Encostas Inferior e Superior do Nordeste, passaram, gradativamente, a migrar para as novas colônias abertas pelo go-

\footnotetext{
${ }^{1}$ Este artigo é uma versão revisada e atualizada de um texto apresentado no $3^{\circ}$ Simpósio Internacional de História Ambiental e Migrações, ocorrido entre os dias 05 e 07 de novembro de 2014 na Universidade Federal de Santa Catarina, em Florianópolis.

${ }^{2}$ Em sua constituição original, o bioma Mata Atlântica cobria praticamente toda a parte norte do Rio Grande Sul, englobando as regiões fisiográficas do Litoral, da Serra Geral, dos Campos de Cima da Serra, do Planalto Médio e do Alto Uruguai (BORGES FORTES, 1959; MARCUZZO et al., 1998).
} 
verno, fenômeno que Jean Roche vai descrever como "o salto para o Planalto" (ESTADO DO RIO GRANDE DO SUL/SECRETARIA ESTADUAL DO MEIO AMBIENTE, 2005, p. 48). Já no século XX, o desmatamento destas áreas potencializou-se a partir da exploração madeireira e pela abertura de novas glebas para a agricultura, especialmente entre os anos $1940 \mathrm{e}$ 1970 (MARCUZZO et al., 1998).

Uma olhada um pouco mais cuidadosa à imagem de satélite também permitirá ao observador identificar, na região que compreende o Alto Uruguai, três pequenas manchas verde-escuras, tal como ilhas solitárias em um mar de lavouras, que atualmente as cercam. Estas áreas não estão lá por mero acaso. São constituídas por um parque florestal estadual, voltado para a preservação da fauna e da flora remanescentes, e duas Terras Indígenas demarcadas pelo governo brasileiro, destinadas às populações Kaingang existentes na região.

O parque florestal é o Parque Estadual do Turvo e fica localizado no município de Derrubadas. Localiza-se em uma área de fronteiras, fazendo divisa com o estado de Santa Catarina e a província de Misiones, Argentina, ambos separados pelo Rio Uruguai. Foi criado em 11 de março de 1947 como uma Reserva Florestal, no governo de Walter Sá Jobim. Tornou-se Parque Estadual em 1954, constituindo-se em uma das primeiras unidades de conservação criadas no Rio Grande do Sul e a maior área de proteção ambiental integral deste estado, com uma área de 17.492 hectares (ESTADO DO RIO GRANDE DO SUL/SECRETARIA ESTADUAL DO MEIO AMBIENTE, 2005, p. 48, 2005, p. 48).

Outra área em que se observam os vestígios da Mata Atlântica resistente na região do Alto Uruguai é a Terra Indígena Guarita, de população majoritariamente Kaingang. Com um total de 23.406,87 hectares, demarcados pelo governo estadual em 1918 e assumida juridicamente pelo Serviço de Proteção aos Índios (SPI) em 1941, a TI Guarita possui na atualidade uma cobertura florestal de aproximadamente $70 \%$ de seu território (ISA, 2014).

A terceira "ilha" que se visualiza no mapa é o objeto principal de análise deste artigo. Pertence hoje à Terra Indígena Nonoai, espaço demarcado em 1911 pela Diretoria de Terras e Colonização do Rio Grande do

\footnotetext{
${ }^{3}$ Embora seja considerada uma área demarcada para os Kaingang, na atualidade existe uma aldeia Guarani que ocupa uma parcela desta Terra Indígena. Este fato é comum em outras áreas indígenas demarcadas para os Kaingang nos estados do RS, SC e PR.
} 
Sul, para abrigar a população Kaingang da região. ${ }^{3}$ Com uma extensão de 34.976 hectares, dos quais cerca de 15.000 destinados à constituição de uma reserva florestal, a área possui uma história repleta de disputas e conflitos em instâncias governamentais, jurídicas e departamentais pela posse do patrimônio territorial e florestal nela existente. É sobre esta história de disputas que versará este texto.

\section{Terra Indígena Nonoai: Aldeamento, Toldo e Posto Indígena}

O espaço de terras hoje denominado Terra Indígena Nonoai, localizado na região noroeste do estado do Rio Grande do Sul, foi criado oficialmente em 1846, no contexto de uma política imperial de aldeamentos. ${ }^{4} \mathrm{Na}$ província gaúcha, os aldeamentos estavam destinados à concentração dos indígenas Coroados (os atuais Kaingang), ocupantes das matas e campos das porções norte e nordeste da província. Para o governo provincial, o principal objetivo da organização de aldeamentos era livrar as áreas próximas a Cruz Alta e Passo Fundo da influência indígena e de suas "correrias", liberando-as para a colonização. Não há evidências exatas sobre o tamanho desta área. Segundo Ligia Simonian e Telmo Marcon, com base em dados cartográficos e documentais do século XIX, é possível que atingisse aproximadamente 360 mil hectares (SIMONIAN, 1981; MARCON, 1994).

Nos primeiros anos do século XX, já sob o regime republicano, o antigo aldeamento indígena tornou-se Toldo Indígena Nonoai, sob a responsabilidade da Secretaria de Negócios e Obras Públicas do RS, cuja subordinada Diretoria de Terras e Colonização (DTC), era responsável pela delimitação e demarcação das reservas indígenas. Neste cenário, o então diretor da DTC, o engenheiro e político positivista Carlos Torres Gonçalves, alcançou destaque por ter organizado, em 1909, o chamado Serviço de Proteção Fraternal aos Indígenas do Rio Grande do Sul (PEZAT, 1997; RODRIGUES, 2007). Este serviço foi criado com a missão de garantir que uma parcela das terras demarcadas

\footnotetext{
${ }^{4}$ Trata-se do "Regulamento acerca das Missões de catequese e civilização dos Índios" (Decreto n. 426 de 24/07/1845), que estabelece as diretrizes gerais da política indigenista do Império. Através do Decreto n. 426, complementam-se as atribuições do Ato Adicional de 12 de maio de 1834, que previa para as assembleias provinciais a função de legislar sobre a catequese e a civilização dos indígenas, e da Lei de 21 de Junho de 1841, que autorizava os governos provinciais a estabelecerem missões nas áreas indígenas. Com o novo Regulamento de 1845 , toda a responsabilidade da catequese e aldeamento dos indígenas fica a cargo das províncias, as quais deveriam criar cargos de Diretores Gerais e Diretores de Aldeamentos. Ver: CUNHA, 1992.
} 
fosse destinada aos indígenas. A partir das demarcações efetuadas pela DTC, Nonoai tem sua área delimitada em 1911, atingindo uma extensão de 34.976 hectares. Composto por campos nativos, entrecortado por matas de araucária e ervais, o Toldo de Nonoai tinha seu território vinculado ao Distrito de Nonoai, então pertencente ao município de Sarandi.

O Serviço de Proteção Fraternal pode ser caracterizado como uma política assistencialista. Tinha como linha mestra garantir a proteção dos indígenas sob dois aspectos principais: em primeiro lugar, no quesito material e, subsequentemente, no aspecto moral. Resumidamente, sob o ponto de vista material, o governo pretendia possibilitar a garantia da subsistência dos indígenas através de seus próprios recursos. Já sob o ponto de vista moral, buscava-se garantir o respeito à sua organização própria, seus costumes e às suas crenças. Todavia, com a destituição de Torres Gonçalves da direção da DTC em 1928, logo após a eleição de Getúlio Vargas à presidência do estado, o Serviço de Proteção Fraternal aos Indígenas do Rio Grande do Sul é praticamente esquecido pelos secretários subsequentes.

A década de 1930 marca, por conseguinte, o fim da política indigenista de influência positivista, uma marca particular de Carlos Torres Gonçalves. Há uma mudança de postura com relação aos indígenas, advinda com as novas políticas do PRR, agora muito mais preocupado em atender às oligarquias rurais e empresas colonizadoras. Nesse momento, de acordo com Lígia Simonian, o estado passa a atuar direta e indiretamente como expropriador oficial das terras dos índios (SIMONIAN, 1981, p. 133). Ocorre, dessa forma, uma invasão acentuada dos territórios indígenas por parte de pequenos posseiros, peões desempregados e, sobretudo, por grandes e médios agricultores em busca de terras para o cultivo agrícola de maior escala, a exemplo do trigo que, à época, surgia como o principal produto cultivado no estado. A grave situação força o governo gaúcho a entregar a tutela dos indígenas do estado à União. Esta, através do Serviço de Proteção aos Índios, inicia em princípios de 1941 a instalação de Postos Indígenas a partir dos já existentes toldos.

\section{A criação da Reserva Florestal de Nonoai}

A instalação de um Posto Indígena pelo SPI em Nonoai causou muitos inconvenientes para alguns moradores da região, sobretudo para comerciantes, agricultores e madeireiros, que usufruíram fartamente da mão 
de obra indígena e dos recursos naturais existentes dentro da área quando da tutela estadual. Estes inconvenientes se deram, em grande parte, porque ao efetivar-se a tutela federal sobre os índios, o governo federal incluía entre seus propósitos a vigilância ao patrimônio existente nas áreas, principalmente do patrimônio florestal. Não foram raros os atritos envolvendo funcionários do SPI e antigos beneficiários dos toldos.

De acordo com informações apresentadas nos relatórios do primeiro encarregado de Nonoai, Francisco Vieira dos Santos, foram frequentes as ameaças sofridas por ele e pelos demais funcionários do SPI, quando se iniciaram os trabalhos de estruturação do Posto Indígena (Ofício-Relatório n. 10 do PIN Nonoai. In: Boletim Interno n. 12, 30 nov. 1942). Além disso, moradores dos arredores incitavam os índios a desobedecerem as novas regras e a abandonarem os serviços. Isso acontecia, segundo Vieira dos Santos, porque a instalação do posto prejudicou alguns indivíduos que usufruíam das terras dos índios para interesses pessoais (Ofício-Relatório $\mathrm{n}^{\circ} 10$ do PIN Nonoai. In: Boletim Interno n. 12, 30 nov. 1942).

O repúdio à instalação de um Posto Indígena não ocorreu apenas em Nonoai. É importante frisar que, na região sul do Brasil, em praticamente todas as áreas indígenas que o SPI passou a administrar a partir de 1941, existiram certos segmentos da sociedade regional que mantinham empreendimentos ou outros interesses no interior das mesmas. Camponeses, comerciantes e madeireiros, em muitos casos, aliavam-se com as próprias lideranças indígenas ou funcionários do estado, visando conseguir autorização para o corte de madeiras dentro das reservas, extração de minérios ou mesmo para o arrendamento de lotes de terras para cultivo.

Sob a administração do SPI, há uma proibição inicial de todas as relações de arrendamentos, associações para extração de madeira ou outras atividades que não tivessem contrato firmado e autorizado pelo próprio órgão indigenista. Isso possibilitou uma relativa proteção às matas existentes nos Postos Indígenas. Como as regiões norte e noroeste do RS apresentavam grande crescimento agropecuário na década de 1940, a cobertura florestal destas áreas foi seriamente atingida. Este fator tornou as áreas indígenas refúgios de mata nativa e, ao mesmo tempo, alvos da cobiça de muitos empresários madeireiros, que viam nestes locais importantes nichos de negociatas.

É importante salientar que o governo estadual tinha ciência desta questão. Por isso mesmo, alegando preocupação com o futuro das matas 
existentes nos Postos Indígenas, o governador Walter Sá Jobim ratifica um decreto sobre ocupação de terras no estado proposto em 1941, pelo então Interventor Osvaldo Cordeiro de Farias. Este decreto reduzia as áreas indígenas demarcadas nos anos de 1911 e 1918, fixando, com base no Regulamento de Terras do RS e à revelia dos interesses das populações indígenas, um novo critério de ocupação nos Postos Indígenas: 75 hectares por família e 25 hectares por índio solteiro e maior de 18 anos (CIMI, 1978, p. 4). As terras excedentes a esse critério seriam destinadas à formação de reservas florestais, sob controle exclusivo do Estado.

Oficialmente, a consolidação desta proposta ocorre com a homologação do Decreto n. 658, de 10 de Março de 1949, o qual destinou cerca de 25 mil hectares pertencentes aos Postos Indígenas Nonoai e Serrinha para o fim de constituírem reservas florestais (SIMONIAN, 1981, p. 138). Somente do Posto Indígena Nonoai, a área destinada à formação da reserva florestal foi de 19.998 hectares, restando ao usufruto dos indígenas os restantes 14.900 hectares. A justificativa do governo estadual era que o SPI, por meio de seus projetos desenvolvimentistas, estava extraindo madeiras das áreas indígenas, o que colocava em risco a conservação da flora típica daquela região (CIMI, 1978, p. 04).

Uma das cláusulas do Decreto n. 658, previa que os indígenas que ocupavam as áreas destinadas à reserva florestal deveriam abandoná-las. A tarefa de remoção das famílias indígenas do parque florestal foi designada ao próprio encarregado do Posto Indígena Nonoai, Francisco Vieria dos Santos, como indica ofício encaminhado ao encarregado pelo Inspetor Florestal Luís Fagundes:

Levamos ao conhecimento de VS. que esta Inspetoria recebeu ordens do Sr. Secretário da Agricultura, Indústria e Comércio, para proceder com urgência a retirada dos selvícolas que moram dentro dos limites da Reserva Florestal lindeira ao Toldo de Nonoai. [...] Sabedores que somos, de que o Serviço de Proteção aos Índios a quem estão subordinados os acima referidos, está sob orientação de SV, vimos pelo presente, solicitar os vossos bons ofícios, no sentido de que seja determinado aos mesmos, se retirarem com urgência da mencionada reserva. [...] Cumpre-nos também vos informar, que a resolução do Sr. Secretário está fundamentada no prejuízo constante que os índios aí habitantes vêm causando anualmente as matas da aludida reserva (BRASIL, Ministério da Agricultura/SPI. Ofício n. 62. 04 jul. 1950).

Cerca de 30 famílias indígenas ocupavam a área. Para agilizar a remoção destas, o Inspetor Florestal solicita a Francisco Vieira que proceda 
urgentemente com a mudança e explicita que, caso não o fizesse e os indígenas se mostrassem reticentes, estava "com ordem de empregar força" (BRASIL, Ministério da Agricultura/SPI. Ofício n. 15, 14 jul. 1951). Mesmo argumentando que a reserva florestal não cumpria com o seu objetivo, pois, não obstante a proteção do estado, estava sendo invadida por empresas agrícolas que exploravam a área para plantio, por caçadores permanentes e exploradores de pedras semipreciosas, Francisco Vieira acaba procedendo a desocupação (BRASIL, Ministério da Agricultura/SPI. Ofício n. 15, 14 jul. 1951).

Lígia Simonian reforça essa afirmação, explicando que, após a demarcação oficial da reserva florestal, esta sofreu "invasões de peões, lavradores, agregados, meeiros, todos expulsos do campo ante a solidificação dos cultivos do trigo e da soja no Estado" (SIMONIAN, 1981, p. 139). O fato destacado por Simonian denota um fenômeno recorrente no RS a partir da década de 1950, quando ocorre o esgotamento das terras destinadas à colonização. Este cenário de escassez de terra potencializa o processo de intrusão nas reservas indígenas e florestais no estado, culminando em mais espoliações.

\section{A espoliação oficial da Reserva Florestal de Nonoai}

Entre 1962 e 1964 o governo do RS promove vários atos de esbulho contra as terras indígenas existentes no estado, fruto de políticas fundiárias contraditórias e excludentes. Para assentar parcelas da população destituída da terra, condenou-se outras a abandonarem as suas. Neste período, vários postos indígenas foram retalhados ou completamente extintos para atenderem à "reforma agrária" promovida pelo governo de Leonel de Moura Brizola (SIMONIAN, 2009; CARINI; TEDESCO, 2012; BRINGMANN, 2015). No tocante à Reserva Florestal de Nonoai, pelo Decreto n. 13.795 de 10 de Julho de 1962, foram designados 2.499 hectares desta para assentamento de camponeses sem terra, totalizando 143 lotes (CIMI, 1978, p. 8). Em princípio, não houve nenhum parecer contrário ao ato governamental por parte do SPI.

Não surpreende a inércia do órgão indigenista federal, pois as inúmeras denúncias que levaram à sua extinção em 1967 incluem favorecimentos a empresas e empresários ante o patrimônio territorial e florestal de diversas áreas indígenas. No caso de Nonoai, ao fomentar a prática dos 
arrendamentos na área do posto, o órgão indigenista alimentava a esperança de uma massa de camponeses excluídos da terra de possuírem sua gleba. Esses camponeses fixavam-se na área e convenciam outras famílias a fazerem o mesmo, ainda que sem contrato firmado com o SPI. O resultado destes arrendamentos possibilitou que, em 1963, houvesse mais camponeses do que indígenas dentro do PI Nonoai, (cerca de 600 famílias camponesas, de acordo com os dados do Conselho Indigenista Missionário) (CIMI, 1978, p. 8).

Do mesmo modo, a concessão de parte da Reserva Florestal de Nonoai para reforma agrária atrai mais camponeses sem terra para a região, muitos dos quais acabam invadindo outras partes desta, além do próprio posto indígena. O próprio secretário da agricultura do RS, Adolfo Fetter, ao tomar conhecimento deste processo por meio da queixa levada a ele pelo cacique de Nonoai, Antônio Nascimento, denuncia a prática: "a reserva de mato, zelada para futura utilização está sendo arrasada pelos intrusos; os índios vêm sofrendo toda sorte de perseguições, espancamentos, destruição dos ranchos e lavouras, por parte dos intrusos" (RIO GRANDE DO SUL/SECRETARIA DE AGRICULTURA, 1963. In: CIMI, 1978, p. 8).

É importante salientar que as invasões contavam com a conivência velada do Instituto Gaúcho de Reforma Agrária (IGRA). Conforme noticiado no Jornal Última Hora, o IGRA, ao não impedir a ocupação da reserva florestal e do Posto Indígena Nonoai, permitiu a existência de uma falsa sensação de segurança aos sem terra que pretendiam lotes nessa área (BRASIL, Ministério da Agricultura/SPI. 21/08/1963, p. 8). Os camponeses sem terra produziram inclusive um documento no qual apresentam suas pretensões nas áreas invadidas. No documento, denominado "Memorial", o presidente da Associação dos Agricultores Sem Terra de Nonoai e Sarandi, Afonso Nunes Barros, informa que existiam aproximadamente 500 colônias vagas na fazenda Sarandi, 750 na Reserva Florestal de Nonoai, 750 no Toldo Nonoai, 100 na reserva da Serrinha. Baseando-se nestes dados, Barros informa que somente na área indígena de Nonoai e na reserva florestal poderiam ser assentadas cerca de 1500 famílias sem terra (RIO GRANDE DO SUL/SECRETARIA DE AGRICULTURA, 1963. In: CIMI, 1978, p. 8).

Como se percebe, já havia estatísticas prontas sobre as áreas, a partir de cálculos que reproduzem o velho lema "muita terra pra pouco índio". Frente a tal situação, paulatinamente vai ocorrendo o abandono do posto 
por parte de muitas famílias indígenas. O capitão dos índios de Nonoai, Vainard Cassemiro, em relato à CPI promovida pela Assembleia Legislativa do RS para apurar o caso em 1967, ressaltou que:

[...] houve luta dos intrusos e índios, sendo que um destes foi morto e vários ficaram feridos; um índio foi assassinado a pedradas [...]. Muitos índios saíram da seção Porongos por causa dos intrusos, indo para a seção Bananeiras ou para Iraí, e outros fugiram para as colônias, extraviados. Os índios recuam a medida que os intrusos avançam ocupando as suas terras. Os intrusos já tomaram a seção de Porongos e cercam a área dos índios por todos os lados [...] (ESTADO DO RIO GRANDE DO SUL/ASSEMBLEIA LEGISLATIVA. CPI 1967/1968, p. 5).

Mediante a gravidade da questão, finalmente o SPI intervém, solicitando obediência à legislação que garante as terras do PI Nonoai aos indígenas. Da mesma forma, a Reserva Florestal passa a ser protegida por legislação estadual, o que faz com que o governo envie tropas da Polícia Militar à região, visando controlar excessos e realizar a retirada dos posseiros, tanto da área indígena quanto da reserva. O aparato policial enviado a Nonoai, entretanto, ao invés de trazer mais tranquilidade para a região e resolver a questão, parece ter piorado a situação, suscitando uma tensão sem precedentes no município e na região:

A operação conjunta da Polícia e da Brigada Militar para acabar com a
manifestação dos camponeses sem terras que acamparam em Passo Feio
terminou com vários incidentes. O acampamento dos "sem terra" foi arra-
sado e incendiado; líderes sindicais porto-alegrenses que para lá se dirigi-
ram, levando mantimentos para os acampados, foram presos e trazidos para
a capital e o prefeito de Nonoai, Jair Calixto, está praticamente prisioneiro
em seu gabinete de trabalho com a cidade ocupada por brigadianos. [...] a
cidade de Nonoai esta virtualmente ocupada pelas forças da Brigada Mili-
tar, que patrulham as ruas armados de fusis e metralhadoras. Nenhum fo-
rasteiro pode transitar pela cidade sem que seja acompanhado por um briga-
diano (ESTADO DO RIO GRANDE DO SUL/ASSEMBLEIA LEGIS-
LATIVA. CPI 1967/1968, p. 5).

A intervenção do estado por meio de sua força policial serviu muito mais para aumentar a violência na região do que para contê-la. Muitos depoimentos apresentados na CPI que investigou a invasão do Posto Indígena e da Reserva Florestal de Nonoai apontam casos de violência e torturas praticados contra camponeses posseiros e contra indígenas.

Após ouvir os depoimentos de representantes dos diversos setores dos governos estadual e federal, como a Secretaria Estadual de Agricultura, SPI, Instituto Brasileiro de Reforma Agrária (IBRA), além de lideran- 
ças indígenas e camponesas, os deputados concluem a CPI, da qual resultam importantes resoluções. Entre as principais, destacam-se as seguintes: a) reconhecimento do direito dos índios nas terras demarcadas; b) recuperação das terras dos índios e reincorporação das áreas destinadas à reserva florestal; c) afastamento de todos os intrusos existentes na área de Nonoai, concedendo-lhes terras em outros locais (Folha da Tarde, 21/12/1967, In: CIMI, 1978, p. 13, SIMONIAN, 1981, p. 148-149). As resoluções desta CPI, no entanto, nunca foram cumpridas, e tanto o PI quanto a Reserva Florestal de Nonoai, assim como várias outras áreas indígenas no Rio Grande do Sul, continuaram ocupadas por posseiros ao longo das décadas de 1960 e 1970.

\section{O florescer do movimento indígena em Nonoai}

A década de 1970 inicia sem grandes avanços no tocante à situação envolvendo posseiros e indígenas, mesmo com a emergência de uma nova agência indigenista no país. ${ }^{5}$ Perante a inércia dos organismos governamentais, a população do Posto Indígena Nonoai organiza-se e passa a reagir de maneira mais ostensiva no sentido de recuperar suas terras.

Em 1974, o clima de tensão na área era grande. Em maio deste ano, o jornal Estado de São Paulo divulgava que "a qualquer momento poderá ocorrer um grave conflito armado entre os 1200 Kaingang de Nonoai e os seis mil agricultores que trabalham nas terras reclamadas pelos índios" (Estado de São Paulo, 17 maio 1974, In: CIMI, 1978, p. 26). O mesmo jornal informou em agosto de 1975 que os Kaingang das áreas indígenas do Rio Grande do Sul "deixam transparecer nos seus atos sua revolta. As ameaças se sucedem e muitos têm partido para a ação direta destruindo roçado dos invasores" (Estado de São Paulo, 30 ago. 1975, In: CIMI, 1978, p. 32).

A situação exigiu medidas urgentes por parte dos governos federal e estadual. Destarte, um grupo de trabalho com representantes da FUNAI, do INCRA e do governo gaúcho é organizado para estudar a questão dos intrusos e arrendatários das áreas indígenas do Rio Grande do Sul. Os dados apresentados pelo grupo, ainda em 1975, indicam que havia mais de

\footnotetext{
${ }^{5}$ A partir de 1967, quando o SPI é extinto após inúmeras denúncias de corrupção contra funcionários, o governo federal rearticula a política indigenista em torno da Fundação Nacional do Índio (FUNAI).
} 
900 famílias camponesas plantando e morando no Posto Indígena Nonoai, o que totalizava 5.207 pessoas. A área ocupada pelas famílias camponesas era de $9.634,2$ hectares, o que equivalia a $64,6 \%$ da área total da reserva (Estado de São Paulo, 30 ago. 1975, In: CIMI, 1978, p. 33). O principal resultado das atividades promovidas pelo GT é que reconheceu a necessidade de restaurar o mais rápido possível a posse da terra aos indígenas.

Entre as ações propostas para evitar o confronto entre índios e posseiros estava o reassentamento dos últimos em outras áreas do estado ou fora dele, em caráter definitivo. Cinco alternativas de locais para reassentamento dos camponeses são elencadas: Polígono de Altamira, PA; Zona de Cáceres, MT; Ariquemes, RO; áreas da União no próprio RS e lotes individuais concedidos por meio de crédito fundiário. Ficou estabelecido também que a retirada dos camponeses caberia inicialmente à FUNAI e o INCRA se incumbiria do reassentamento das famílias (Estado de São Paulo, 30 ago. 1975, In: CIMI, 1978, p. 34-35). Obviamente houve muita resistência por parte de posseiros, muitos dos quais assentados há anos na área indígena e constituindo considerável patrimônio.

Assim como ocorreu com a CPI de 1967, as ações do grupo de trabalho reverberaram muito mais em ações de gabinete do que em medidas práticas e efetivas. Frente ao marasmo das desocupações por parte dos órgãos competentes, entre os anos de 1976 e 1977, os indígenas de Nonoai passaram a se organizar através de comissões de índios formadas para pressionar diretamente os presidentes da FUNAI e da República para uma solução definitiva. Os indígenas contaram com muitas adesões à causa, principalmente por parte de entidades religiosas, como a Pastoral da Terra e o Conselho Indigenista Missionário (CIMI). Contaram ainda com apoio de setores ligados a universidades, por meio de antropólogos, sociólogos e indigenistas, que passaram a atuar no sentido de defender as áreas indígenas (CARINI; TEDESCO, 2012, p. 46).

O antagonismo entre índios e camponeses se acirrou em 1978, quando, no mês de maio, após inúmeras assembleias e reuniões, os Kaingang levam a cabo medidas drásticas para pressionar os posseiros a abandonarem a área. Entre as primeiras ações computadas estão os incêndios nas escolas, consideradas fortes mecanismos retentores dos posseiros na área indígena (SIMONIAN, 1981, p. 177). Foram sete as escolas rurais queimadas, que haviam sido construídas pelas prefeituras das cidades limítrofes do posto indígena. Na sequência, armando-se de porretes, arcos e flechas, lan- 
ças e algumas armas de fogo, os Kaingang deram início ao processo de expulsão dos quase três mil camponeses que ainda ocupavam suas terras (FERNANDES, 2003, p. 220-221)

Como lembra Simonian, grupos de índios sem número específico eram organizados e armados para darem a "ordem de saída" (SIMONIAN, 1981, p. 184). A Brigada Militar intervinha nas ações, vigiando o despejo movido pelos indígenas. Estes, por seu turno, continuaram a cobrar os prazos dados aos posseiros, que, em sua maioria, saíam às pressas da área, instalando-se nos arredores das cidades de Planalto e Nonoai. Abrigavamse em acampamentos provisórios ou nas casas de conhecidos, até a definição de um local onde seriam reassentados (CIMI, 1978, p. 100-101, CARINI; TEDESCO, 2012, p. 49).

No final do mês de maio de 1978, aproximadamente 500 famílias já haviam abandonado a área indígena. Os Kaingang assumiram a tarefa de reconstruí-la, organizando-se para ocupá-la efetivamente e iniciar a caminhada para uma recuperação ambiental, cultural e populacional. Entre as lideranças, consolidou-se o discurso de criar condições necessárias para o retorno de muitas famílias indígenas que, desde a intensificação da intrusão, haviam-se espalhado pelo Rio Grande do Sul, por Santa Catarina e pelo Paraná (CIMI, 1978, p. 101). Foi neste momento que a Reserva Florestal de Nonoai começa a ser requisitada pelos Kaingang de maneira mais enfática.

\section{Considerações finais: a retomada da Reserva Florestal de Nonoai como símbolo da luta indígena}

Após a reconquista da terra, os Kaingang denunciaram e confrontaram a exploração efetuada pela própria FUNAI, através do Departamento Geral do Patrimônio Indígena (DGPI), órgão responsável pelos projetos de desenvolvimento agropecuário nas áreas indígenas brasileiras. O DGPI produzia soja no PI Nonoai e a renda obtida raramente era revertida em benefício da comunidade indígena. No tocante à Reserva Florestal de Nonoai, embora tenha sido sugerida sua reintegração à área indígena pela CPI de 1967, nenhuma ação nesse sentido correu ao longo das décadas de 1970 e 1980. A reserva florestal continuava vigiada por guardas florestais que impediam a entrada dos indígenas. 
Cansados da espera e das promessas governamentais de que a reserva voltaria ao controle dos indígenas de Nonoai, as lideranças deste posto começam um movimento de reivindicação bastante forte entre o final dos anos 1980 e início de 1990. Em 1992, cerca de 250 indígenas, entre os quais muitas mulheres e crianças, rompem o cerco da guarda florestal e reocupam a reserva, onde permanecem acampados por vários anos, enquanto o processo corria na justiça (ZERO HORA, 17 fev. 1992). Ao mesmo tempo em que se negociava o retorno da reserva florestal para os Kaingang, entidades ecológicas do RS e SBPC mobilizaram-se para impedir que o governo estadual devolvesse a área à comunidade indígena. Sua justificativa era de que a reserva havia sido destruída ao longo dos anos pelos próprios índios, ao permitirem a caça predatória, as queimadas criminosas e a exploração de pedras semipreciosas e madeira (CORREIO BRAZILIENSE, 22 jan. 1994).

Não obstante os inúmeros protestos por parte de ONGs ambientalistas e instituições de ensino e pesquisa do estado, no ano de 2003, a Reserva Florestal de Nonoai é finalmente devolvida à população Kaingang e Guarani de Nonoai, através do Decreto Presidencial n. 03, de 10 de fevereiro de 2003 (BRASIL, 2003).

No cômputo geral desse processo, algumas reflexões merecem lugar na finalização deste texto. Ao analisar o processo de criação da Reserva Florestal de Nonoai, é possível observar uma atuação incisiva do governo do estado do RS como expropriador oficial dos indígenas em dois momentos principais. Primeiramente, com a demarcação de uma reserva florestal à revelia dos interesses indígenas. Mesmo sabendo tratar-se desta área uma das mais importantes fontes de coleta de matéria-prima para a confecção de artesanato e de alimentos de origem vegetal e animal pelos índios, o governo fixa decretos excludentes e fornece forte aparato policial para impedir a entrada destes na área. Da mesma forma, é o próprio estado que atua como espoliador oficial, permitindo invasões e depredações por parte de posseiros, intrusos ou arrendatários, ou mesmo concedendo uma boa parcela da reserva para o assentamento dos sem terra, promovendo uma reforma agrária em terras pertencentes aos indígenas.

Neste contexto, o SPI e a FUNAI se mostram extremamente inoperantes, sendo ora coniventes com as ações do governo gaúcho, ora esquivando-se de suas responsabilidades para a defesa dos direitos territoriais da população que atendiam. Por conta disso, é possível afirmar que a recuperação da reserva e sua redemarcação como área indígena é fruto muito 
mais das pressões protagonizadas pelos índios, por meio de mobilizações políticas e ações armadas, do que por ações das agências indigenistas que parecem ter abandonado as prerrogativas pelas quais foram criadas.

Com relação ao destino da reserva, apesar de homologada em 2003, vários recursos tramitam na justiça para que a área hoje conhecida como Terra Indígena Nonoai-Rio da Várzea retorne ao estado como reserva florestal. Cerca de 400 indígenas ocupam este espaço atualmente, onde mantêm roçados de subsistência e coletam material para produção de artesanato. O cacique desta TI, José Lopes do Nascimento, garante que existe uma ocupação sustentável da área, afirmando inclusive que mantém uma guarda indígena para protegê-la de madeireiros, caçadores e mineradores.

Quanto ao receio de ecologistas de que a reserva seria devastada, isto não se confirmou. Percebe-se que, desde 2003, não se registraram grandes impactos na sua flora, a qual mantém uma cobertura florestal em ótimo estado de conservação. Todavia, não há dados que possam garantir o mesmo com relação à fauna. Em se tratando de cobertura florestal, conforme destacado no início do artigo, as imagens atuais de satélite permitem observar a sua permanência praticamente intacta, mantendo-se como uma pequena ilha isolada em meio às lavouras que a circundam.

\section{Referências}

BORGES FORTES, Amyr. Aspectos Fisiográficos, Demográficos e Econômicos do Rio Grande do Sul. Serviço Social da Indústria, 1959.

BRASIL, Presidência da República. Decreto de 10 fev. 2003. Disponível em: <http:// legis.senado.gov.br/legislacao/ListaTextoIntegral.action?id=223612\&norma $=236213>$. Acesso em: 12 fev. 2017.

BRINGMANN, Sandor Fernando. Entre os Índios do Sul: Uma análise da atuação indigenista do SPI e de suas propostas de desenvolvimento educacional e agropecuário nos Postos Indígenas Nonoai/RS e Xapecó/SC (1941-1967). Tese (Doutorado em História), Universidade Federal de Santa Catarina, Centro de Filosofia e Ciências Humanas, Florianópolis, 2015.

CARINI, Joel João. Estado, Índios e Colonos: o conflito na reserva indígena de Serrinha - norte do Rio Grande do Sul. Passo Fundo: Editora UPF, 2005.

CARINI, Joel; TEDESCO, João Carlos. O Conflito de Nonoai: um marco na história de lutas pela terra. In: ZARTH, Paulo A. (Org.). História do Campesinato na Fronteira Sul. Porto Alegre: Letra \& Vida; Chapecó: Universidade Federal da Fronteira Sul, 2012, p. 33-57. 
CIMI. Boletim Luta Indígena: informativo dos índios e missionários do Sul do Brasil. n. 6. Xanxerê, ago. 1978.

CORREIO BRAZILIENSE. Ambientalistas denunciam queimada no Parque Nonoai, p. 14, 22 jan. 1994. Disponível em: <https://documentacao.socioambiental.org/ noticias/anexo_noticia/12065_20100514_104423.pdf>. Acesso em: $12 \mathrm{fev} .2017$. CUNHA, Manuela C. da (Org.). História dos Índios no Brasil. São Paulo: Companhia das Letras, 1992.

FERNANDES, Ricardo Cid. Politica e Parentesco entre os Kaingang: uma análise etnológica. Tese (Doutorado em Antropologia Social), Universidade de São Paulo, São Paulo, 2003.

ISA. Instituto Socioambiental. Terra Indigena Guarita. Disponível em: <http:// www. socioambiental.org>. Acesso em: 12 set. 2014.

SIMONIAN, Ligia T. L. Terra de Posseiros: um estudo sobre as políticas de terras indígenas. Dissertação (Mestrado em Antropologia Social). Museu Nacional, UFRJ, 1981.

SIMONIAN, Ligia T. L. Política/ação anti-indigena de Leonel de Moura Brizola. In: GOLIN, Tau; BOEIRA, Nelson (Orgs.). Povos Indigenas. Passo Fundo: Méritos, 2009. p. 469-496. (Coleção História Geral do Rio Grande do Sul, 5).

MARCON, Telmo (Org.). História e cultura Kaingang no sul do Brasil. Passo Fundo: Ed. UPF, 1994.

MARCUZZO, Silvia; PAGEL, Sílvia Mara; CHIAPETTI, Maria Isabel Stumpf. $A$ reserva da biosfera da Mata Atlântica no Rio Grande do Sul: situação atual, ações e perspectivas. São Paulo: Conselho Nacional da Reserva da Biosfera da Mata Atlântica, 1998. (Série Estados e Regiões da RBMA, 11).

PEZAT, Paulo Ricardo. Auguste Comte e os fetichistas: estudo sobre as relações entre a Igreja Positivista do Brasil, o Partido Republicano Rio-Grandense e a política indigenista na República Velha. Dissertação (Mestrado em História), UFRGS, Porto Alegre, 1997.

ROCHE, Jean. A colonização alemã e o Rio Grande do Sul. Porto Alegre: Editora Globo, 2 v. 1969.

RODRIGUES, Cíntia Régia. As populações nativas sob a luz da modernidade: a proteção fraterna no Rio Grande do Sul (1908-1928). Tese (Doutorado em História). Unisinos, São Leopoldo, 2007.

ANAIS $8^{a}$ Assembleia dos Chefes Indígenas. Depoimento do chefe Kaingang Candetê. Ijuí/RS. 16 a 18 abr. 1977, p. 28. Disponível em: <http://www.docvirt.com/ docreader.net>. Acesso em: 12 fev. 2017.

BRASIL, Ministério da Agricultura/SPI. Oficio n. 62 da Secretaria da Indústria e Comércio do RS ao encarregado do PI Nonoai Francisco Vieira dos Santos. Erechim. 4 jul. 1950. Microfilme 058. Fotograma 1326. SEDOC/Museu do Índio-RJ. 
BRASIL, Ministério da Agricultura/SPI. Oficio n. 15 do encarregado do PI Nonoai Francisco Vieira a Dival José de Souza, Chefe da IR7. Nonoai. 14 jul. 1951. Microfilme 058. Fotograma 11425 a 1427. SEDOC/Museu do Índio-RJ.

BRASIL, Ministério da Agricultura/SPI. Recortes Jornal Última Hora. 21 ago. 1963. p. 8. Microfilme 059. Fotograma 0143. SEDOC/Museu do Índio-RJ.

ESTADO DO RIO GRANDE DO SUL/ASSEMBLEIA LEGISLATIVA. CPI para apurar a situação em que se encontram os índios do Toldo Nonoai e os chamados "agricultores sem terra". Porto Alegre, 1967/1968.

ESTADO DO RIO GRANDE DO SUL/SECRETARIA ESTADUAL DO MEIO AMBIENTE. Plano de manejo do Parque Estadual do Turvo. Porto Alegre, 2005.

RELATÓRIO 25/08/1914. Relatório da Diretoria de Terras e Colonização de 9 de julho de 1914, publicado no Relatório da Secretaria de Estado das Obras Públicas apresentado ao presidente Antonio Augusto Borges de Medeiros, presidente do Estado do Rio Grande do Sul em 25 de agosto de 1914. Porto Alegre: Officinas Graphicas da Livraria do Globo, 1914.

RELATÓRIO 07/1930. Relatório da Diretoria de Terras e Colonização de 1929, publicado no Relatório da Secretaria de Estado das Obras Públicas apresentado ao presidente Getúlio Vargas, presidente do Estado do Rio Grande do Sul em Julho de 1930. Porto Alegre: Officinas graphicas d'A Federação. 1930, p. 766.

WESTPHALEN, Moysés. Reforma Agrária nas Terras dos Índios. Jornal Correio do Povo. 3 jul. 1963. p. 9. Arquivo do Museu de Comunicação Social Hipólito José da Costa MCSHJC/Porto Alegre-RS.

ZERO HORA. Índios querem área do Parque Florestal. 17 fev. 1992. Disponível em: <https://documentacao.socioambiental.org/noticias/anexo_noticia/ 11792_20100507_091317.pdf>. Acesso em: 12 fev. 2017.

\section{Fontes}

BRASIL, Ministério da Agricultura/SPI. Boletim Interno n. 4. 2 fev. 1942. SEDOC/ Museu do Índio-RJ.

BRASIL, Ministério da Agricultura/SPI. Boletim Interno n. 12.30 nov. 1942. SEDOC/ Museu do Índio-RJ.

BRASIL, Ministério da Agricultura/SPI. Boletim Interno n. 14.31 jan. 1943. SEDOC/ Museu do Índio-RJ.

BRASIL, Ministério da Agricultura/SPI. Boletim Interno n. 17.30 abr. 1943. SEDOC/ Museu do Índio-RJ.

BRASIL, Ministério da Agricultura/SPI. Boletim Interno n. 22.30 set. 1943. SEDOC/ Museu do Índio-RJ. 